\title{
Relationship of the 1793G-A and 677C-T polymorphisms of the 5,10-methylenetetrahydrofolate reductase gene to coronary artery disease
}

\author{
Cory B. Kebert ${ }^{\mathrm{a}}$, June E. Eichner ${ }^{\mathrm{b}}$, William E. Moore ${ }^{\mathrm{b}}$, Eliot Schechter ${ }^{\mathrm{c}}$, Takuro Yaoi ${ }^{\mathrm{d}}$, Steve Vogel ${ }^{\mathrm{a}}$, \\ Richard A. Allen ${ }^{\mathrm{a}}$ and S. Terence Dunn ${ }^{\mathrm{a}, *}$ \\ ${ }^{a}$ Department of Pathology, University of Oklahoma Health Sciences Center, Oklahoma City, OK, 73104, USA \\ ${ }^{\mathrm{b}}$ University of Oklahoma Prevention Research Center, University of Oklahoma Health Sciences Center, Oklahoma \\ City, OK 73104, USA \\ ${ }^{\mathrm{c}}$ Department of Medicine, University of Oklahoma Health Sciences Center, Oklahoma City, OK 73104, USA \\ ${ }^{\mathrm{d}}$ FreshGene, Inc., 200 Mason Circle, Suite C, Concord, CA 94520, USA
}

\begin{abstract}
Numerous studies have investigated the relationship between polymorphisms, in particular 677C-T and 1298A-C, of the methylene-tetrahydrofolate reductase (MTHFR) gene and coronary artery disease (CAD) with conflicting results. This study investigates the potential association of two point mutations in $M T H F R, 677 \mathrm{C}-\mathrm{T}$ and $1793 \mathrm{G}-\mathrm{A}$, along with other risk factors, with CAD. This is the first hospital-based study to investigate 1793G-A in this context. Genotype analysis was performed on 729 Caucasians and 66 African Americans undergoing coronary angiography using a novel PCR-based assay involving formation of Holliday junctions. Allelic frequencies for $677 \mathrm{C}-\mathrm{T}$ were $66.2 \% \mathrm{C}$ and $33.8 \% \mathrm{~T}$ for Caucasians and $90.9 \% \mathrm{C}$ and $9.1 \% \mathrm{~T}$ for African Americans. With respect to the 1793G-A polymorphism, allelic frequencies were $94.7 \% \mathrm{G}$ and $5.3 \%$ A for Caucasians and $99.2 \% \mathrm{G}$ and $0.8 \% \mathrm{~A}$ for African Americans. Disease associations were examined in the Caucasian patients due to their greater genotype variability and larger number in the patient cohort. Results suggest that neither 677CT heterozygotes (OR-1.36; 95\% CI 0.95 to 1.96) nor mutant homozygotes (OR-0.73; 95\% CI 0.44 to 1.20 ) have either an increased or decreased risk for CAD compared to the 677CC genotype. Likewise, the 1793GA genotype did not demonstrate a statistically significant association with CAD compared to $1793 \mathrm{GG}$ patients (OR-0.79; $95 \%$ CI 0.47 to 1.33 ). Mean homocysteine levels ( $\mu$ mol/L) increased from normal to mutant for 677C-T (677CC: 10.2; 677CT: 11.0; 677TT: 11.6) and normal to heterozygous in 1793G-A (1793GG: 10.7; 1793GA: 11.5). These MTHFR polymorphisms did not contribute to the prediction of clinically defined CAD in Caucasians.
\end{abstract}

Keywords: Methylenetetrahydrofolate reductase, MTHFR, CAD, C677T, G1793A, atherosclerosis, homocysteine, Holliday junction

\section{Introduction}

Methylenetetrahydrofolate reductase $(M T H F R)$ has the important role in folate metabolism of catalyz-

*Corresponding author: Department of Pathology, University of Oklahoma Health Sciences Center, 940 Stanton L. Young Blvd., Oklahoma City, OK 73104, USA. Tel.: +1 405 2715249; Fax: +1 405 2713881; E-mail: terry-dunn@ouhsc.edu. ing the conversion of 5,10-methylenetetrahydrofolate to 5-methyltetrahydrofolate which is required for the remethylation of homocysteine to methionine. Two common polymorphisms, 677C-T and 1298A-C, have been described as causing thermolability and reduced enzyme activity $[9,15,16,41]$. Homozygosity for $677 \mathrm{C}$ T, homozygosity for 1298A-C and compound heterozygosity have been shown to reduce MTHFR enzyme activity in vitro to $45 \%, 68 \%$, and $41 \%$, respectively [42]. 
With a decrease in proper functioning, hyperhomocysteinemia can occur which has been recognized as an independent risk factor for arteriosclerotic vascular disease unrelated to hyperlipidemia, hypertension, diabetes, and smoking [2,26]. Currently, 677C-T and 1298A-C polymorphisms have been linked to coronary artery disease (CAD) [8,20,21,24,25,29,36]; while a third, 1793G-A, has yet to be studied in this context.

Studies relating MTHFR polymorphisms to CAD have produced conflicting results. While several studies have found positive associations $[8,20,21,24,25,29$, $36]$, others have not $[1,4,18,27,37,46]$. Some studies have even suggested that hyperhomocysteinemia may actually be a consequence of cardiovascular disease rather than a causal factor [3,28]. Folate levels have also been extensively studied, and moderate to high plasma folate levels have been shown to reduce the incidence of acute coronary events [40]. Also, the $677 \mathrm{C}-\mathrm{T}$ mutant genotype along with low folate levels has been associated with increases in plasma homocysteine levels [11,13]. Klerk et al. [19] reported in their meta-analysis that individuals with $677 \mathrm{C}-\mathrm{T}$ and low folate status had a significantly higher risk of CAD. In combined analysis of European studies ( $n=6207)$, CAD risk for the TT mutant genotype was increased $14 \%$ over the CC wild-type genotype. By comparison, analysis of the North American studies $(n=3146)$ did not show such a relationship and even suggested a protective association with CAD (OR 0.87). One of the speculations of this study was that, with higher dietary intakes of folate, there might be no adverse effect on plasma homocysteine levels or subsequent risk of coronary heart disease. In addition to an association with CAD, MTHFR polymorphisms have been associated with arterial and venous thromboembolism [10, 17], diabetes [12,35], neural tube defects [5,39], breast cancer [32,33], and lung cancer [31]. Possible protective effects of $677 \mathrm{C}-\mathrm{T}$ have been shown against colon cancer [22,23].

A novel polymorphism of MTHFR, 1793G-A, was first described by Rady et al. [30] who reported polymorphism frequencies in US Caucasians, AfricanAmericans, Hispanics, and Ashkenazi Jews. This polymorphism was found to have a lower allelic frequency in comparison to $677 \mathrm{C}-\mathrm{T}$ and $1298 \mathrm{~A}-\mathrm{C}$. It is unknown whether $1793 \mathrm{G}-\mathrm{A}$ polymorphism causes a decrease in MTHFR enzyme activity, however, in a recent study of kidney transplant recipients, it was suggested that 1793G-A may have a stabilizing, rather than destabilizing, effect on MTHFR activity [43]. To the best of our knowledge, there have been no studies that have looked at a possible association of this polymorphism with CAD. In the present study, we investigate the role of two MTHFR polymorphisms, 677C-T and 1793G-A in a population of 795 patients receiving coronary angiography in an attempt to examine a possible role in CAD.

\section{Materials and methods}

\subsection{Study population}

Consenting consecutive men and women $(n=795)$ undergoing coronary angiography at Veterans Affairs Medical Center (VAMC) and the University Hospital (Oklahoma City, OK) between November 1992 and March 1994, were enrolled in the study, as approved by the Institutional Review Board at The University of Oklahoma Health Sciences Center. The 795 patients included 604 Caucasian men, 125 Caucasian women, 51 African American men, and 15 African American women. Most patients were undergoing catheterization for angina; however, other indications included previous MI, aortic stenosis, aortic or mitral regurgitation, and atypical chest pain. Coronary angiography was performed using standard techniques. Measurements and views taken during the procedure have been described previously [7]. Severity of vessel obstruction was graded visually by two independent cardiologists in the view in which it was most severe. Other CAD risk factors were obtained by review of angiography reports and medical records.

\subsection{Laboratory methods}

Fifty-five milliters of blood were collected at the time of coronary angiography through the arterial sheath prior to administration of heparin. Total cholesterol, HDL cholesterol, and triglycerides were measured on EDTA plasma samples using the Centers for Disease Control standardized protocols. Genomic DNA was isolated from blood by a standard proteinase Kphenol-chloroform extraction method. The presence of single nucleotide polymorphisms (SNP) in the 5,10methylenetetrahydrofolate reductase $($ MTHFR) gene was determined at positions 677 (C-T) and 1793 (GA) using a novel one-step Holliday junction-based allele-specific genotyping technology (MTHFR Polymorphism Genotyping Sample Kits, Cat. No. 100001 and 100005; FreshGene Inc., Concord, CA) described previously [45]. Briefly, each $10 \mu \mathrm{L}$ reaction contained 
AmpliTaq Gold ${ }^{\mathrm{TM}}$ (Perkin Elmer, Wellesley, MA), dNTPs, primers flanking the substitution sites, approximately $1 \mathrm{ng}$ of DNA and the following amplification parameters performed in a Biometra T-Gradient Thermoblock (Whatman, Göttingen, Germany): $94^{\circ} \mathrm{C}$ initial denaturation then 45 cycles of $94^{\circ} \mathrm{C}$ denaturation for $15 \mathrm{sec}, 58^{\circ} \mathrm{C}$ primer annealing for $23 \mathrm{sec}$, and $72^{\circ} \mathrm{C}$ extension for $45 \mathrm{sec}$, as per the manufacturers instructions. Two reactions were run per SNP for each patient sample (i.e., a $\mathrm{C}$ tube and a $\mathrm{T}$ tube for the 677C-T analysis and a $G$ tube and an A tube for the 1973G-A analysis). For each SNP, a total of five primers were used: three short forward primers and two reverse primers. One forward primer is used to produce "target amplicons" in conjunction with the pair of reverse primers. The other two forward primers are designed to be complementary for either allele 1 or allele 2 of each SNP and to produce "reference amplicons" in conjunction with the reverse primers. Either a "normal" or "mutant" reference primer is placed in the two reactions. The forward primers and the two reverse primers are designed with complementary tails in order to encourage the formation of 4-stranded cruciform structures, or Holliday junctions $(\mathrm{HJ})$ in subsequent steps. Following thermal cycling, PCR products were subject to denaturation at $95^{\circ} \mathrm{C}$ for 2 mins then a branch migration step for HJ formation at $62^{\circ} \mathrm{C}$ for 30 mins. During this process the allele-specific reference amplicons hybridize with the target amplicons to give $\mathrm{HJ}$ products depending on the presence of a complementary target (i.e., normal or mutant allele). The reference primers were constructed with 3' ends that introduced a single base mismatch before each SNP in order to impede branch migration and cause the formation of stable HJ products. In addition, reference primers had GC-clamps at the 5' ends to aid in $\mathrm{HJ}$ formation. HJ products were then analyzed by electorphoretic separation on 3\% Super Fine Resolution (Amresco, Solon, Ohio) agarose or $6 \%$ precast TBE PAGE (InVitrogen Inc., Carlsbad, CA) gels stained with SYBR-Gold (Molecular Probes, Eugene, OR). Each PCR run included a no-DNA control to monitor for carry-over contamination and a known SNP heterozygote to verify optimal performance of each reaction set. "Blind" processing of 24 duplicate samples for each polymorphism analyzed served as an internal control of genotype specificity and assay reproducibility. In addition, genotypes of 20 samples were verified independently by separate PCR-RFLP analysis, as previously described $[9,30]$.

\subsection{Statistical methods}

For the purposes of description and analysis, we created two separate data sets; one containing all genotyped subjects (729 Caucasians and 66 African Americans) and the other with African Americans omitted to be used for logistic regression modeling. We performed chi-square tests for independence on the complete data set to determine the relationship between race and MTHFR polymorphism. For logistic regression analysis, the sample was further restricted due to incomplete data on some patients. Since African Americans represented a small portion of our overall patient group and moreover, because $M T H F R$ allelic frequencies in this ethnic group were divergent from Caucasians, the final data set used for CAD analysis comprised 706 Caucasians. We also calculated mean homocysteine levels by MTHFR polymorphism on a reduced subset with available data $(n=393)$.

We generated crude and adjusted odds ratios to determine the risk for CAD associated with each MTHFR polymorphism. The adjusted logistic regression model included age, sex, diabetes, fibrinogen, triglycerides, non-HDLc, and smoking status as potential confounders of the relationship between MTHFR polymorphisms and CAD. Patients were dichotomized into those without disease (no stenosis equal or greater than $50 \%$ ) and those with disease (at least one stenosis greater or equal to $50 \%$ ). Lastly, the amount of vessel disease was also quantified for each patient by summing the values of all the identified stenoses; a term we refer to as the "atherosclerosis score".

\section{Results}

\subsection{Prevalence of $677 C-T$ and $1793 G-A$ polymorphisms}

Of the 795 patients genotyped, there were 381 (47.9\%) 677CC wild-types, 323 (40.6\%) 677CT heterozygotes, and $91(11.4 \%)$ homozygous $677 \mathrm{TT}$ mutants (Table 1). The $1793 \mathrm{G}-\mathrm{A}$ polymorphism was less frequent than the 677C-T (Table 2); allelic frequency was $78 / 1590(4.9 \%)$ for all patients. There were 717 patients $(90.2 \%)$ with the $1793 \mathrm{GG}$ wild-type genotype and $78(9.8 \%)$ 1793GA heterozygotes. There were no homozygous 1793AA mutant individuals detected in the cohort analyzed. There were 29 677CT/1793GA compound heterozygotes. The distribution of compound genotypes within the total patient data set is 
Table 1

Frequency of 677C-T genotypes in coronary angiography patients by race and gender

\begin{tabular}{|c|c|c|c|}
\hline & $\begin{array}{c}\text { Caucasian } \\
\text { n (column \%) }\end{array}$ & $\begin{array}{l}\text { African American } \\
\text { n (column } \%)\end{array}$ & $\begin{array}{c}\text { All races } \\
\mathrm{n}(\text { column \%) }\end{array}$ \\
\hline \multicolumn{4}{|l|}{ Males and females } \\
\hline Normal & $326(44.7 \%)$ & $55(83.3 \%)$ & $381(47.9 \%)$ \\
\hline Heterozygotes & $313(42.9 \%)$ & $10(15.2 \%)$ & $323(40.6 \%)$ \\
\hline Homozygotes & $90(12.3 \%)$ & $1(1.5 \%)$ & $91(11.4 \%)$ \\
\hline Total $($ row \%) & $729(91.7 \%)$ & $66(8.3 \%)$ & 795 \\
\hline \multicolumn{4}{|c|}{ Chi-square test for independence, $36.5_{2 \mathrm{df}}, p<0.001$} \\
\hline \multicolumn{4}{|c|}{ Males } \\
\hline Normal & $262(43.4 \%)$ & $42(82.3 \%)$ & $304(46.4 \%)$ \\
\hline Heterozygotes & $270(44.7 \%)$ & $8(15.7 \%)$ & $278(42.4 \%)$ \\
\hline Homozygotes & $72(11.9 \%)$ & $1(2.0 \%)$ & $73(11.1 \%)$ \\
\hline Total $($ row \%) & $604(92.2 \%)$ & $51(7.8 \%)$ & 655 \\
\hline \multicolumn{4}{|c|}{ Chi-square test for independence, $28.9_{2 \mathrm{df}}, p<0.001$} \\
\hline \multicolumn{4}{|c|}{ Females } \\
\hline Normal & $64(51.2 \%)$ & $13(86.7 \%)$ & $77(55 \%)$ \\
\hline Heterozygotes & $43(34.4 \%)$ & $2(13.3 \%)$ & $45(32.1 \%)$ \\
\hline Homozygotes & $18(14.4 \%)$ & $0(0.0 \%)$ & $18(12.9 \%)$ \\
\hline Total $($ row \%) & $125(89.3 \%)$ & $15(10.7 \%)$ & 140 \\
\hline
\end{tabular}

Table 2

Frequency of $1793 \mathrm{G}$-A genotypes in coronary angiography patients by race and gender

\begin{tabular}{|c|c|c|c|}
\hline Patient & $\begin{array}{c}\text { Caucasian } \\
\text { n }(\text { column \%) }\end{array}$ & $\begin{array}{c}\text { African American } \\
\text { n (column } \%)\end{array}$ & $\begin{array}{c}\text { All races } \\
\text { n }(\text { column \%) }\end{array}$ \\
\hline \multicolumn{4}{|l|}{ Males and females } \\
\hline Normal & $652(89.4 \%)$ & $65(98.5 \%)$ & $717(90.2 \%)$ \\
\hline Heterozygotes & $77(10.6 \%)$ & $1(1.5 \%)$ & $78(9.8 \%)$ \\
\hline Homozygotes & $0(0.0 \%)$ & $0(0.0 \%)$ & $0(0.0 \%)$ \\
\hline Total $($ row \%) & $729(91.7 \%)$ & $66(8.3 \%)$ & 795 \\
\hline \multicolumn{4}{|c|}{ Chi-square test for independence, $5.6_{1 \mathrm{df}}, p=0.018$} \\
\hline \multicolumn{4}{|c|}{ Males } \\
\hline Normal & $542(89.7 \%)$ & $50(98.0 \%)$ & $592(90.4 \%)$ \\
\hline Heterozygotes & $62(10.3 \%)$ & $1(2.0 \%)$ & $63(9.6 \%)$ \\
\hline Homozygotes & 0 & 0 & 0 \\
\hline Total (row \%) & $604(92.2 \%)$ & $51(7.8 \%)$ & 655 \\
\hline \multicolumn{4}{|c|}{ Chi-square test for independence, $3.7_{1 \mathrm{df}}, p=0.053$} \\
\hline \multicolumn{4}{|c|}{ Female } \\
\hline Normal & $110(88.0 \%)$ & $15(100 \%)$ & $125(89.3 \%)$ \\
\hline Heterozygotes & $15(12 \%)$ & 0 & $15(10.3 \%)$ \\
\hline Homozygotes & 0 & 0 & 0 \\
\hline Total (row \%) & $125(89.3 \%)$ & $15(10.7 \%)$ & 140 \\
\hline
\end{tabular}

presented in Table 3. There were significantly fewer African Americans with either mutation as compared to Caucasians (Tables 1 and 2). Allelic frequencies for 677C-T were $66.2 \% \mathrm{C}$ and $33.8 \% \mathrm{~T}$ for Caucasians and $90.9 \% \mathrm{C}$ and $9.1 \% \mathrm{~T}$ for African Americans. With respect to the $1793 \mathrm{G}-\mathrm{A}$ polymorphism, allelic frequencies were $94.7 \% \mathrm{G}$ and $5.3 \% \mathrm{~A}$ for Caucasians and 99.2\% $\mathrm{G}$ and $0.8 \% \mathrm{~A}$ for African Americans. The differences in $677 \mathrm{C}-\mathrm{T}$ and $1793 \mathrm{G}-\mathrm{A}$ frequencies between Caucasians and African Americans were statistically significant when considering the overall popula- tion (Tables 1 and 2), but there were no significant differences in the frequencies of the $1793 \mathrm{G}$-A polymorphism between these groups when considering males or females only.

\section{2. $677 C$-T and $1793 G$-A polymorphisms and $C A D$}

Logistic regression analysis of Caucasian patients produced an odds ratio indicating that 677CT heterozygotes do not have an increased risk of disease compared to $677 \mathrm{CC}$ individuals (Crude OR-1.36; 95\% CI 
Table 3

Distribution of compound genotypes in coronary angiography patients

$\begin{array}{lcccc}\mathrm{n} & 677 \mathrm{CC} & 677 \mathrm{CT} & 677 \mathrm{TT} & \text { Totals } \\ 1793 \mathrm{GG} & 332 & 294 & 91 & 717 \\ 1793 \mathrm{GA} & 49 & 29 & 0 & 78 \\ 1793 \mathrm{AA} & 0 & 0 & 0 & 0 \\ \text { Totals } & 381 & 323 & 91 & 795\end{array}$

0.95 to 1.96 ) (Table 4). Likewise, 677TT homozygous Caucasians do not have a reduced risk for disease when compared to normal 677CC individuals (Crude OR$0.73 ; 95 \%$ CI 0.44 to 1.20$)$. Although point estimates diverged from 1.00 , the $95 \%$ confidence intervals included 1.00 in both cases. Logistic regression analysis of the less frequent $1793 \mathrm{G}-\mathrm{A}$ polymorphism produced an odds ratio for CAD that was not statistically significant as compared to the normal genotype (Crude OR-0.79; 95\% CI 0.47 to 1.33). The results for both polymorphisms were consistent for crude odds ratios and those generated from a model including potential confounders: age, sex, diabetic status, smoking status, fibrinogen, lipid profile and triglycerides. Overall, MTHFR genotype did not demonstrate any statistically significant association with the presence of atherosclerosis using the clinical definition of one or more stenosis $\geqslant 50 \%$ in any of the 3 major coronary arteries. Lastly, a descriptive table of possible confounding variables in this population was generated for completeness and future investigators (Table 5).

\section{3. $677 C$-T and $1793 G$-A polymorphisms, CAD and homocysteine}

Homocysteine levels were obtained on 393 patients. The mean Hcy levels $(\mu \mathrm{mol} / \mathrm{L})$ in our population included 677CC: 10.2; 677CT: 11.0; 677TT: 11.6; 1793GG: 10.7; 1793GA: 11.5 (Table 6). These levels increase in a mutation dose-dependent manner for both the $677 \mathrm{C}-\mathrm{T}$ and the $1793 \mathrm{G}-\mathrm{A}$ mutations.

\section{Discussion}

\subsection{Prevalence of $677 C-T$ and $1793 G-A$ polymorphisms}

The 677C-T genotype (CC-47.9\%, CT-40.6\%, TT$11.4 \%)$ and allelic frequencies $(31.8 \%)$ for all races found in our predominately Caucasian population are similar to those reported for other populations [20, $37,38]$, including a recent meta-analysis [19]. The allelic frequency amongst African Americans in our population $(9.1 \%)$ was similar to those described for other African American populations [6,30,34]. Few studies have investigated the population prevalence of the $1793 \mathrm{G}-\mathrm{A}$ polymorphism. The $1793 \mathrm{G}-\mathrm{A}$ polymorphism had lower frequencies in our Caucasian patient population (GG-89.4\%, GA-10.6\%, AA-0\%; allelic frequency- $5.3 \%$ ) as compared to the $677 \mathrm{C}-\mathrm{T}$ polymorphism. A recent Austrian study [44] of 1793G-A, with a similar patient sample size $(n=733)$ and likely Caucasian-enriched, had similar findings (GG-89.9\%, GA-9.9\%, AA-0.3\%; allelic frequency- 5.2\%). Rady et al. [30] studied the distribution of the $1793 \mathrm{G}-\mathrm{A}$ polymorphism amongst several ethnic groups and found that allelic frequencies were highest amongst Caucasians (6.9\%), lowest in Ashkenazi Jews (1.3\%) and intermediate in Hispanics (5.8\%) and African-Americans (3.1\%). Allelic frequencies for the 1793G-A polymorphism in our population were slightly lower for Caucasians $(5.3 \%)$ and substantially lower for African Americans (0.8\%). Although other studies have documented homozygous 1793AA mutants (1/507 [30]; $2 / 733$ [43]), this genotype was absent from our patient group despite the larger cohort size.

Compound 677CT/1793GA heterozygotes were present in $3.6 \%$ of our cohort (Table 3 ). It is unclear whether these mutated alleles existed in cis or trans; however, of the ninety-one 677TT homozygous mutants, none had a $1793 \mathrm{G}-\mathrm{A}$ polymorphism, which suggests that mutated alleles generally reside in trans conformation. In addition, other studies have failed to document 677CT/1793AA genotype combinations [30]. Isotalo et al. [14] postulated that $677 \mathrm{CT} / 1298 \mathrm{CC}$ and 677TT/1298CC genotypes, which contain three and four mutated alleles respectively, may compromise fetal viability especially during times of folate insufficiency and therefore would be very rare in the population. Clearly, evaluation of any potential synergistic effect of 677C-T, 1298A-C, 1793G-A in cis and trans will require study of a large cohort considering the low prevalence of compound heterozygotes and homozygous mutants in the general population.

\section{2. $677 C-T$ and $1793 G$-A polymorphisms and CAD}

Numerous studies have been completed relating MTHFR polymorphisms to CAD with $677 \mathrm{C}-\mathrm{T}$ being studied in most detail followed by $1298 \mathrm{~A}-\mathrm{C}$. While many have shown risk associations $[8,20,21,24,25,29$, $36]$, others have not $[1,4,18,27,37,46]$. Unfortunately, we were unable to complete analysis of the 1298A-C 
Table 4

Crude and adjusted* Odds Ratios for CAD by MTHFR genotype among Caucasian coronary angiography patients

\begin{tabular}{|c|c|c|}
\hline $\mathrm{n}=706$ & Adjusted odds ratio $(95 \% \mathrm{CI})$ & Crude odds ratio $(95 \% \mathrm{CI})$ \\
\hline $677 \mathrm{CC}$ & 1.0 & 1.0 \\
\hline $677 \mathrm{CT}$ & $1.41(0.93$ to 2.12$)$ & $1.36(0.95$ to 1.96$)$ \\
\hline $677 \mathrm{TT}$ & $0.69(0.39$ to 1.23$)$ & $0.73(0.44$ to 1.20$)$ \\
\hline Age (1 Year) & $1.07(1.04$ to 1.09$)$ & \\
\hline Diabetes (Yes) & 2.03 (1.25 to 3.29$)$ & \\
\hline Fibrinogen $(1 \mathrm{mg} / \mathrm{dL})$ & $1.003(1.002$ to 1.005$)$ & \\
\hline NonHDLc (1 mg/dL) & 1.004 (1.0001 to 1.008$)$ & \\
\hline Sex (Male) & $4.44(2.72$ to 7.23$)$ & \\
\hline Smoker (Current v. never) & $1.90(1.02$ to 3.53$)$ & \\
\hline Triglycerides (1 mg/dL) & $1.003(1.001$ to 1.005$)$ & \\
\hline $\mathrm{n}=706$ & Adjusted odds ratio $(95 \% \mathrm{CI})$ & Crude odds ratio $(95 \% \mathrm{CI})$ \\
\hline $1793 \mathrm{GG}$ & 1.0 & 1.0 \\
\hline 1793 GA & $0.80(0.44$ to 1.44$)$ & $0.79(0.47$ to 1.33$)$ \\
\hline Age (1 Year) & 1.07 (1.04 to 1.09$)$ & \\
\hline Diabetes (Yes) & $2.03(1.25$ to 3.29$)$ & \\
\hline Fibrinogen $(1 \mathrm{mg} / \mathrm{dL})$ & $1.003(1.002$ to 1.005$)$ & \\
\hline NonHDLc (1 mg/dL) & $1.004(1.0005$ to 1.008$)$ & \\
\hline Sex (Male) & $4.45(2.80$ to 7.41$)$ & \\
\hline Smoker (Current v. never) & $1.92(1.03$ to 3.56$)$ & \\
\hline Triglycerides (1 mg/dL) & $1.003(1.001$ to 1.005$)$ & \\
\hline
\end{tabular}

Table 5

Descriptive statistics for possible continuous confounding factors (mean and standard error) and possible categorical confounding factors (\%) for CAD and MTHFR genotype in Caucasian coronary angiography patients $(n=706)$

\begin{tabular}{|c|c|c|c|c|c|c|c|c|c|c|}
\hline \multirow{2}{*}{$\begin{array}{l}\text { Continuous variables } \\
\text { mean (s.e.) }\end{array}$} & \multicolumn{2}{|c|}{$677 \mathrm{CC}$} & \multicolumn{2}{|c|}{$677 \mathrm{CT}$} & \multicolumn{2}{|c|}{$677 \mathrm{TT}$} & \multicolumn{2}{|c|}{$1793 \mathrm{GG}$} & \multicolumn{2}{|c|}{ 1793GA } \\
\hline & CAD & No CAD & CAD & No CAD & CAD & No CAD & CAD & No CAD & CAD & No CAD \\
\hline Age (years) & $\begin{array}{l}60.56 \\
(0.65)\end{array}$ & $\begin{array}{l}54.39 \\
(1.04)\end{array}$ & $\begin{array}{l}59.74 \\
(0.64)\end{array}$ & $\begin{array}{l}53.13 \\
(1.18)\end{array}$ & $\begin{array}{l}58.43 \\
(1.30)\end{array}$ & $\begin{array}{l}57.40 \\
(1.81)\end{array}$ & $\begin{array}{l}59.92 \\
(0.45)\end{array}$ & $\begin{array}{l}54.70 \\
(0.77)\end{array}$ & $\begin{array}{l}60.31 \\
(1.38)\end{array}$ & $\begin{array}{l}52.13 \\
(2.07)\end{array}$ \\
\hline Number of stenoses (Count) & $\begin{array}{c}6.64 \\
(0.18)\end{array}$ & $\begin{array}{c}1.39 \\
(0.29)\end{array}$ & $\begin{array}{c}6.71 \\
(0.18)\end{array}$ & $\begin{array}{c}1.34 \\
(0.33)\end{array}$ & $\begin{array}{c}5.74 \\
(0.36)\end{array}$ & $\begin{array}{c}1.83 \\
(0.51)\end{array}$ & $\begin{array}{c}6.47 \\
(0.13)\end{array}$ & $\begin{array}{c}1.41 \\
(0.21)\end{array}$ & $\begin{array}{c}7.56 \\
(0.38)\end{array}$ & $\begin{array}{c}1.65 \\
(0.58)\end{array}$ \\
\hline Atherosclerosis score* & $\begin{array}{l}405.09 \\
(12.51)\end{array}$ & $\begin{array}{c}34.00 \\
(20.12)\end{array}$ & $\begin{array}{l}404.58 \\
(12.32)\end{array}$ & $\begin{array}{c}33.73 \\
(22.67)\end{array}$ & $\begin{array}{l}350.09 \\
(25.07)\end{array}$ & $\begin{array}{c}46.67 \\
(34.86)\end{array}$ & $\begin{array}{r}393.13 \\
(8.71)\end{array}$ & $\begin{array}{c}34.61 \\
(14.71)\end{array}$ & $\begin{array}{l}451.54 \\
(26.44)\end{array}$ & $\begin{array}{c}45.22 \\
(39.75)\end{array}$ \\
\hline Total cholesterol (mg/dL) & $\begin{array}{r}225.75 \\
(3.82)\end{array}$ & $\begin{array}{r}213.21 \\
(6.15)\end{array}$ & $\begin{array}{r}222.28 \\
(3.77)\end{array}$ & $\begin{array}{r}209.27 \\
(6.93)\end{array}$ & $\begin{array}{r}226.81 \\
(7.67)\end{array}$ & $\begin{array}{l}217.77 \\
(10.66)\end{array}$ & $\begin{array}{r}224.85 \\
(2.66)\end{array}$ & $\begin{array}{r}211.96 \\
(4.50)\end{array}$ & $\begin{array}{r}219.15 \\
(8.09)\end{array}$ & $\begin{array}{l}216.13 \\
(12.16)\end{array}$ \\
\hline NonHDLc (mg/dL) & $\begin{array}{r}194.47 \\
(3.82)\end{array}$ & $\begin{array}{r}179.47 \\
(6.15)\end{array}$ & $\begin{array}{r}190.68 \\
(3.77)\end{array}$ & $\begin{array}{r}174.66 \\
(6.92)\end{array}$ & $\begin{array}{r}195.38 \\
(7.66)\end{array}$ & $\begin{array}{c}183.17 \\
(10.65)\end{array}$ & $\begin{array}{r}193.39 \\
(2.66)\end{array}$ & $\begin{array}{r}178.48 \\
(4.50)\end{array}$ & $\begin{array}{r}187.92 \\
(8.08)\end{array}$ & $\begin{array}{l}176.70 \\
(12.15)\end{array}$ \\
\hline Triglycerides (mg/dL) & $\begin{array}{r}202.07 \\
(9.94)\end{array}$ & $\begin{array}{l}179.06 \\
(15.99)\end{array}$ & $\begin{array}{r}198.08 \\
(9.79)\end{array}$ & $\begin{array}{l}155.61 \\
(18.00)\end{array}$ & $\begin{array}{l}241.71 \\
(19.91)\end{array}$ & $\begin{array}{l}182.83 \\
(27.69)\end{array}$ & $\begin{array}{r}203.91 \\
(6.94)\end{array}$ & $\begin{array}{l}173.38 \\
(11.72)\end{array}$ & $\begin{array}{l}210.92 \\
(21.07)\end{array}$ & $\begin{array}{l}153.09 \\
(31.68)\end{array}$ \\
\hline Fibrinogen $(\mathrm{mg} / \mathrm{dL})$ & $\begin{array}{r}385.34 \\
(8.72)\end{array}$ & $\begin{array}{l}333.02 \\
(14.04)\end{array}$ & $\begin{array}{r}376.15 \\
(8.64)\end{array}$ & $\begin{array}{l}331.10 \\
(15.95)\end{array}$ & $\begin{array}{l}366.59 \\
(17.70)\end{array}$ & $\begin{array}{l}340.33 \\
(24.18)\end{array}$ & $\begin{array}{r}375.87 \\
(6.08)\end{array}$ & $\begin{array}{l}339.48 \\
(10.26)\end{array}$ & $\begin{array}{c}409.23 \\
(18.28)\end{array}$ & $\begin{array}{l}290.43 \\
(27.49)\end{array}$ \\
\hline $\begin{array}{l}\text { Categorical variables \% } \\
\text { Diabetes }\end{array}$ & & & & & & & & & & \\
\hline Current smokers & 48.9 & $\begin{array}{l}22.2 \\
48.9\end{array}$ & 56.3 & $\begin{array}{r}0.1 \\
54.9\end{array}$ & 44.8 & $\begin{array}{l}20.1 \\
56.7\end{array}$ & 50.1 & $\begin{array}{l}10.1 \\
52.4\end{array}$ & $\begin{array}{l}50.0 \\
67.3\end{array}$ & 52.2 \\
\hline
\end{tabular}

* Atherosclerosis score $=$ Sum of blockages in coronary arteries.

polymorphism for this cohort due to technical problems encountered during the design of primers for this specific Holliday junction assay. Moreover, due to the constraints imposed on analysis by the low numbers of African Americans included in the cohort, the present study is limited to investigation of possible associations between CAD and two polymorphisms of MTHFR, 677C-T and 1793G-A, in Caucasians only. To the au- thors' knowledge, this is the first study to look at the association between 1793G-A and CAD.

Surprisingly, although our results suggest that 677CT heterozygotes have a slightly increased (albeit not significant) risk of disease compared to $677 \mathrm{CC}$ individuals (Crude OR-1.36; 95\% CI 0.95 to 1.96 ), the mutant TT population did not (Crude OR-0.73; 95\% CI 0.44 to 1.20 , respectively). Clearly, one would expect 
Table 6

Homocysteine levels associated with 677C-T and 1793G-A genotypes in Caucasian coronary angiography patients $(\mathrm{n}=393)$

$\begin{array}{lc}\text { mean (s.e.) } & \text { Homocysteine } \mu \mathrm{mol} / \mathrm{L} \\ 677 \mathrm{CC} & 10.2(0.4) \\ 677 \mathrm{CT} & 11.0(0.4) \\ 677 \mathrm{TT} & 11.6(0.7) \\ 1793 \mathrm{GG} & 10.7(0.3) \\ 1793 \mathrm{GA} & 11.5(0.7)\end{array}$

to see a mutation dose-related response if indeed the 677C-T polymorphism plays a significant role in predisposition to CAD. The 1793GA population demonstrated a statistically non-significant protective association with CAD compared to the $1793 \mathrm{GG}$ patients (Crude OR-0.79; 95\% CI 0.47 to 1.33 ).

A recent meta-analysis has provided convincing evidence that low folate status, resulting in high homocysteine levels, causes an increased risk for CAD in 677C-T mutants [19]. In this study, European patients with the mutant 677TT genotype had an OR of 1.14. Conversely, North American subjects, who were expected to be well nourished and with higher dietary folate and vitamin usage than that of the Europeans, were slightly protected by the mutation and had an OR of 0.87. In 1996, the US Food and Drug Administration permitted voluntary fortification of enriched cereal and grain products, and in January 1998 required that all enriched grain products contain $140 \mathrm{mcg}$ of folic acid per $100 \mathrm{~g}$. Therefore, our patient population may not have benefited from dietary folate supplementation since they underwent coronary angiography between November 1992 and March 1994 and had their blood samples drawn at that time for the laboratory values indicated in this paper. In this sense, our cohort probably has a folate status resembling that of European patients. However, the mutant 677TT genotype was associated with a crude OR of 0.73 in our population and an OR of 1.14 in the meta-analysis of Europeans [19]. Unfortunately, the initial design of the study of our patient population in relation to CAD did not anticipate investigation of markers related to MTHFR metabolism, so we do not have folate levels gathered on these patients. However, considering the fact that these patients were studied at a time prior to folate supplementation, it is likely that their dietary folate intake was sub-optimal and their homocysteine levels accordingly elevated. Indeed, we found an increasing trend of homocysteine levels: $10.2,11.0,11.6 \mu \mathrm{mol} / \mathrm{L}$ in $677 \mathrm{CC}, 677 \mathrm{CT}$ and 677TT individuals, respectively (Table 6). An increasing trend was also seen in our $1793 \mathrm{G}-\mathrm{A}$ population: $10.7 \mu \mathrm{mol} / \mathrm{L}$ for $1793 \mathrm{GG}$ and $11.5 \mu \mathrm{mol} / \mathrm{L}$ for $1793 \mathrm{GA}$.
While functional studies have confirmed the effects of 677C-T and 1298A-C polymorphisms on MTHFR thermolability, similar studies have not been performed on MTHFR containing the $1793 \mathrm{G}-\mathrm{A}$ mutation. If the $1793 \mathrm{G}-\mathrm{A}$ polymorphism were to cause enzyme instability and decreased activity, we would expect homocysteine levels to be higher, especially in those with low folate status. Although homocysteine levels demonstrated a dose-response for both mutations, these values are probably too low to have independently contributed to any significant cardiovascular effect.

Our findings confirm previous studies that the 677C$\mathrm{T}$ polymorphism probably contributes only minimally, if at all, to an increased risk for CAD in Caucasians. The MTHFR $1793 \mathrm{G}-\mathrm{A}$ polymorphism likely contributes no risk for CAD in Caucasians.

\section{Acknowledgements}

Patient enrollment and collection and processing of specimens were supported by Oklahoma Center for the Advancement of Science and Technology HS2-025 and American Heart Association Oklahoma Affiliate 93078550 (JEE). MTHFR genotyping was made possible by funds from the Department of Pathology Research Studentship (CK and SV) and by the Clarence and Matilda Bower Memorial Fund.

\section{References}

[1] K.K. Abu-Amero, C.A. Wyngaard and N. Dzimiri, Prevalence and role of methylenetetrahydrofolate reductase $677 \mathrm{C} \rightarrow \mathrm{T}$ and $1298 \mathrm{~A} \rightarrow \mathrm{C}$ polymorphisms in coronary artery disease in Arabs, Archives of Pathology \& Laboratory Medicine 127 (2003), 1349-1352.

[2] C.J. Boushey, S.A. Beresford, G.S. Omenn and A.G. Motulsky, A quantitative assessment of plasma homocysteine as a risk factor for vascular disease. Probable benefits of increasing folic acid intakes, Journal of the American Medical Association 274 (1995), 1049-1057.

[3] L. Brattstrom and D.E. Wilcken, Homocysteine and cardiovascular disease: cause or effect? The American Journal of Clinical Nutrition 72 (2000), 315-323.

[4] E.S. Brilakis, P.B. Berger, K.V. Ballman and R. Rozen, Methylenetetrahydrofolate reductase (MTHFR) 677C $>\mathrm{T}$ and methionine synthase reductase (MTRR) $66 \mathrm{~A}>\mathrm{G}$ polymorphisms: association with serum homocysteine and angiographic coronary artery disease in the era of flour products fortified with folic acid, Atherosclerosis 168 (2003), 315-322.

[5] B. Christensen, L. Arbour, P. Tran, D. Leclerc, N. Sabbaghian, R. Platt, B.M. Gilfix, D.S. Rosenblatt, R.A. Gravel, P. Forbes and R. Rozen, Genetic polymorphisms in methylenetetrahydrofolate reductase and methionine synthase, folate levels in red blood cells, and risk of neural tube defects, American Journal of Human Genetics 84 (1999), 151-157. 
[6] A. Dilley, W.C. Hooper, M. El-Jamil, M. Renshaw, N.K. Wenger and B.L. Evatt, Mutations in the genes regulating methylene tetrahydrofolate reductase $($ MTHFR $\mathrm{C} \rightarrow \mathrm{T} 677)$ and cystathione beta-synthase (CBS G $\rightarrow$ A919, CBS $\mathrm{T} \rightarrow \mathrm{C} 833$ ) are not associated with myocardial infarction in African Americans, Thrombosis Research 103 (2001), 109-115.

[7] J.E. Eichner, V.J. Christiansen, W.E. Moore, S.T. Dunn and E. Schechter, Angiotensin-converting enzyme gene polymorphism in a cohort of coronary angiography patients, Atherosclerosis 154 (2001), 673-679.

[8] O. Fletcher and A.M. Kessling, MTHFR association with arteriosclerotic vascular disease? Human Genetics 103 (1998), 11-21.

[9] P. Frosst, H.J. Blom, R. Milos, P. Goyette, C.A. Sheppard, R.G. Matthews, G.J.H. Boers, M. den Heijer, L.A.J. Kluijtmans, L.P. van den Heuvel and R. Rozen, A candidate genetic risk factor for vascular disease: a common mutation in methylenetetrahydrofolate reductase, Nature Genetics $\mathbf{1 0}$ (1995), 111-113.

[10] D. Gemmati, M.L. Serino, C. Trivellato, S. Fiorini and G.L. Scapoli, C677T substitution in the methylenetetrahydrofolate reductase gene as a risk factor for venous thrombosis and arterial disease in selected patients, Haematologica 84 (1999), 824-828.

[11] D. Girelli, N. Martinelli, F. Pizzolo, S. Friso, O. Olivieri, C. Stranieri, E. Trabetti, G. Faccini, E. Tinazzi, P.F. Pignatti and R. Corrocher, The interaction between MTHFR 677 $\mathrm{C} \rightarrow \mathrm{T}$ genotype and folate status is a determinant of coronary atherosclerosis risk, The Journal of Nutrition 133 (2003), 1281-1285.

[12] G. Hasegawa, H. Obayashi, K. Kamiuchi, M. Nakai, T. Kanatsuna, M. Yamaguchi, T. Tanaka, H. Shigeta, M. Fujii, T. Yoshikawa and N. Nakamura, The association between endstage diabetic nephropathy and methylenetetrahydrofolate reductase genotype with macroangiopathy in type 2 diabetes mellitus, Experimental and Clinical Endocrinology \& Diabetes 111 (2003), 132-138.

[13] H.J. Huh, H.S. Chi, E.H. Shim, S. Jang and C.J. Park, Genenutrition interactions in coronary artery disease: Correlation between the MTHFR C677T polymorphism and folate and homocysteine status in a Korean population, Thrombosis Research (2005), Epub ahead of print.

[14] P.A. Isotalo, G.A. Wells and J.G. Donnelly, Neonatal and fetal methylenetetrahydrofolate reductase genetic polymorphisms: an examination of C677T and A1298C mutations, American Journal of Human Genetics 67 (2000), 986-990.

[15] S.-S. Kang, J. Zhou, P.W.K. Wong, J. Kowalisyn and G. Strokosch, Intermediate homocysteinemia: a thermolabile variant of methylenetetrahydrofolate reductase, American Journal of Human Genetics 43 (1988), 414-421.

[16] S.-S. Kang, P.W.K. Wong, A. Susmano, J. Sora, M. Norusis and N. Ruggie, Thermolabile methylenetetrahydrofolate reductase: an inherited risk factor for coronary artery disease, American Journal of Human Genetics 48 (1991), 536-545.

[17] P.J. Kelly, J. Rosand, J.P. Kistler, V.E. Shih, S. Silveira, A. Plomaritoglou and K.L. Furie, Homocysteine, MTHFR 677C $\rightarrow \mathrm{T}$ polymorphism, and risk of ischemic stroke: results of a metaanalysis, Neurology 59 (2002), 529-536.

[18] C.H. Kim, K.Y. Hwang, T.M. Choi, W.Y. Shin and S.Y. Hong, The methylenetetrahydrofolate reductase gene polymorphism in Koreans with coronary artery disease, International Journal of Cardiology 78 (2001), 13-17.

[19] M. Klerk, P. Verhoef, R. Clarke, H.J. Blom, F.J. Kok and E.G. Schouten, MTHFR Studies Collaboration Group. MTHFR
$677 \mathrm{C} \rightarrow \mathrm{T}$ polymorphism and risk of coronary heart disease: a meta-analysis, Journal of the American Medical Association 288 (2002), 2023-2031.

[20] L.A. Kluijtmans, J.J. Kastelein, J. Lindemans, G.H. Boers, S.G. Heil, A.V. Bruschke, J.W. Jukema, L.P. van den Heuvel, F.J. Trijbels, G.J. Boerma, F. W. Verheugt, F. Willems and H.J. Blom, Thermolabile methylenetetrahydrofolate reductase in coronary artery disease, Circulation 96 (1997), 2573-2577.

[21] L.A. Kluijtmans, L.P. van den Heuvel, G.H. Boers, P. Frosst, E.M. Stevens, B.A. van Oost, M. den Heijer, F.J. Trijbels, R. Rozen and H.J. Blom, Molecular genetic analysis in mild hyperhomocysteinemia: a common mutation in the methylenetetrahydrofolate reductase gene is a genetic risk factor for cardiovascular disease, American Journal of Human Genetics $\mathbf{5 8}$ (1996), 35-41.

[22] L. Le Marchand, L.R. Wilkens, L.N. Kolonel and B.E. Henderson, The MTHFR C677T polymorphism and colorectal cancer: the multiethnic cohort study, Cancer Epidemiology, Biomarkers, \& Prevention 14 (2005), 1198-1203.

[23] J. Ma, M.J. Stampfer, E. Giovannucci, C. Artigas, D.J. Hunter, C. Fuchs, W.C. Willet, J. Selhub, C.H. Hennekens and R. Rozen, Methylenetetrahydrofolate reductase polymorphism, dietary interactions, and risk of colorectal cancer, Cancer Research 57 (1997), 1098-1102.

[24] A. Mager, S. Lalezari, T. Shohat, Y. Birnbaum, Y. Adler, N. Magal and M. Shohat, Methylenetetrahydrofolate reductase genotypes and early-onset coronary artery disease, Circulation 100 (1999), 2406-2410.

[25] H. Morita, J. Taguchi, H. Kurihara, M. Kitaoka, H. Kaneda, Y. Kurihara, K. Maemura, T. Shindo, T. Minamino, M. Ohno, K. Yamaoki, K. Ogasawara, T. Aizawa, S. Suzuki and Y. Yazaki, Genetic polymorphism of 5,10-methylenetetrahydrofolate reductase $(M T H F R)$ as a risk factor for coronary artery disease, Circulation 95 (1997), 2032-2036.

[26] A.G. Motulsky, Nutritional ecogenetics: homocysteinerelated arteriosclerotic vascular disease, neural tube defects, and folic acid, American Journal of Human Genetics $\mathbf{5 8}$ (1996), 17-20.

[27] K. Nakai, C. Itoh, K. Nakai, W. Habano and D. Gurwitz, Correlation between C677T MTHFR gene polymorphism, plasma homocysteine levels and the incidence of CAD, American Journal of Cardiovascular Drugs: Drugs, Devices, and Other Interventions 1 (2001), 353-361.

[28] O. Nygard, S.E. Vollset, H. Refsum, L. Brattstrom and P.M. Ueland, Total homocysteine and cardiovascular disease, Journal of Internal Medicine 246 (1999), 425-454.

[29] D.A. Payne, A.J. Chamoun, S.I. Seifert and G.A. Stouffer, MTHFR $677 \mathrm{C} \rightarrow$ T mutation: a predictor of early-onset coronary artery disease, Thrombosis Research 103 (2001), 275279.

[30] P.L. Rady, S. Szucs, J. Grady, S.D. Hudnall, L.H. Kellner, H. Nitowsky, S.K. Tyring and R.K. Matalon, Genetic polymorphisms of methylenetetrahydrofolate reductase (MTHFR) and methionine synthase reductase (MTRR) in ethnic populations in Texas; a report of a novel MTHFR polymorphic site, G1793A, American Journal of Human Genetics 107 (2002), 162-168.

[31] Q. Shi, Z. Zhang, G. Li, P.C. Pillow, L.M. Hernandez, M.R. Spitz and Q. Wei, Sex differences in risk of lung cancer associated with methylene-tetrahydrofolate reductase polymorphisms, Cancer Epidemiology, Biomarkers \& Prevention 14 (2005), 1477-1484.

[32] M.J. Shrubsole, X.O. Shu, Z.X. Ruan, Q. Cai, H. Cai, Q. Niu, Y.T. Gao and W. Zheng, MTHFR genotypes and breast cancer 
survival after surgery and chemotherapy: a report from the Shanghai Breast Cancer Study, Breast Cancer Research and Treatment 91 (2005), 73-79.

[33] M.J. Shrubsole, Y.T. Gao, Q. Cai, X.O. Shu, Q. Dai, J.R. Hebert, F. Jin and W. Zheng, MTHFR polymorphisms, dietary folate intake, and breast cancer risk: results from the Shanghai Breast Cancer Study, Cancer Epidemiology, Biomarkers \& Prevention 13 (2004), 190-196.

[34] R.E. Stevenson, C.E. Schwartz, Y.Z. Du and M.J. Adams Jr, Differences in methylenetetrahydrofolate reductase genotype frequencies, between Whites and Blacks, American Journal of Human Genetics 60 (1997), 229-230.

[35] J. Sun, Y. Xu, Y. Zhu and H. Lu, Genetic polymorphism of methylenetetrahydrofolate reductase as a risk factor for diabetic nephropathy in Chinese type 2 diabetic patients, Diabetes Research and Clinical Practice 64 (2004), 185-190.

[36] A. Szczeklik, M. Sanak, M. Jankowski, J. Dropinski, R. Czachor, J. Musial, I. Axenti, M. Twardowska, T. Brzostek and M. Tendera, Mutation A1298C of methylenetetrahydrofolate reductase: risk for early coronary disease not associated with hyperhomocysteinemia, American Journal of Human Genetics 101 (2001), 36-39.

[37] F.M. van Bockxmeer, C.D. Mamotte, S.D. Vasikaran and R.R. Taylor, Methylenetetrahydrofolate reductase gene and coronary artery disease, Circulation 95 (1997), 21-23.

[38] N.M. van der Put, F. Gabreels, E.M. Stevens, J.A. Smeitink, F.J. Trijbels, T.K. Eskes, L.P. van den Heuvel and H.J. Blom, A second common mutation in the methylenetetrahydrofolate reductase gene: an additional risk factor for neural-tube defects? American Journal of Human Genetics 62 (1998), 1044-1051.

[39] N.M.J. van der Put, T.K.A.B. Eskes and H.J. Blom, Is the common $677 \mathrm{C} \rightarrow \mathrm{T}$ mutation in the methylenetetrahydrofolate reductase gene a risk factor for neural tube defects? A metaanalysis, The Quarterly Journal of Medicine 90 (1997), 111115
[40] S. Voutilainen, T.H. Rissanen, J. Virtanen, T.A. Lakka and J.T. Salonen, Kuopio Ischemic Heart Disease Risk Factor Study. Low dietary folate intake is associated with an excess incidence of acute coronary events: The Kuopio Ischemic Heart Disease Risk Factor Study, Circulation 103 (2001), 26742680.

[41] I. Weisberg, P. Tan, B. Christensen, S. Sibani and R. Rozen, A second genetic polymorphism in methylenetetrahydrofolate reductase (MTHFR) associated with decrease enzyme activity, Molecular Genetics and Metabolism 64 (1998), 169-172.

[42] I.S. Weisberg, P.F. Jacques, J. Selhub, A.G. Bostom, Z. Chen, R. Curtis Ellison, J.H. Eckfeldt and R. Rozen, The $1298 \mathrm{~A} \rightarrow \mathrm{C}$ polymorphism in methylenetetrahydrofolate reductase (MTHFR): in vitro expression and association with homocysteine, Atherosclerosis 156 (2001), 409-415.

[43] W.C. Winkelmayer, A. Huber, O.F. Wagner, W.H. Horl, G. Sunder-Plassmann and M. Fodinger, Associations between MTHFR $1793 \mathrm{G}>\mathrm{A}$ and plasma total homocysteine, folate, and vitamin B in kidney transplant recipients, Kidney International 67 (2005), 1980-1985.

[44] W.C. Winkelmayer, G. Sunder-Plassmann, A. Huber and M. Fodinger, Patterns of co-occurrence of three single nucleotide polymorphisms of the 5,10-methylenetetrahydrofolate reductase gene in kidney transplant recipients, European Journal of Clinical Investigation 34 (2004), 613-618.

[45] Q. Yang, A. Lishanski, W. Yang, S. Hatcher, H. Seet and J. Gregg, Allele-specific Holliday junction formation - a new mechanism of allelic discrimination for SNP scoring, Genome Research 13 (2003), 1754-1764.

[46] H. Yilmaz, S. Isbir, B. Agachan, A. Ergen, B. Farsak and T. Isbir, C677T mutation of methylenetetrahydrofolate reductase gene and serum homocysteine levels in Turkish patients with coronary artery disease, Cell Biochemistry and Function (2005), Epub ahead of print. 


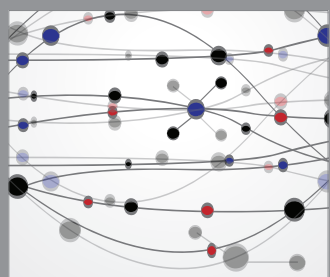

The Scientific World Journal
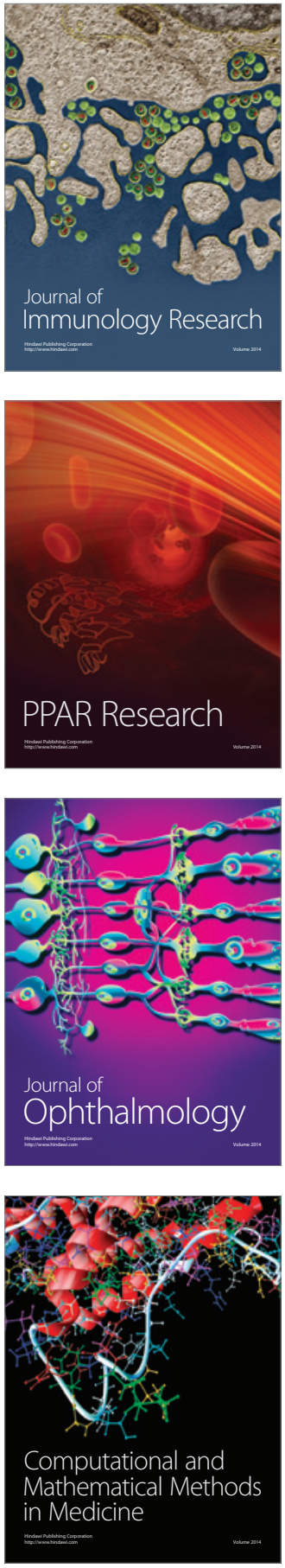

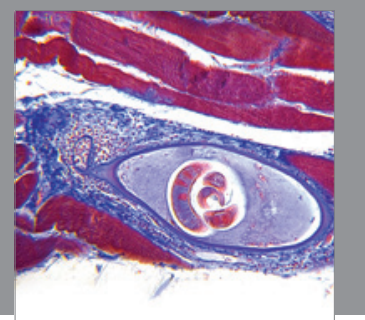

Gastroenterology

Research and Practice
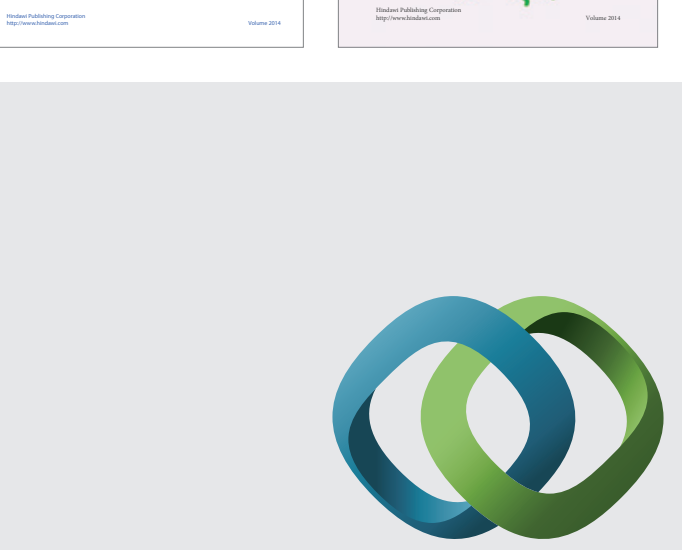

\section{Hindawi}

Submit your manuscripts at

http://www.hindawi.com
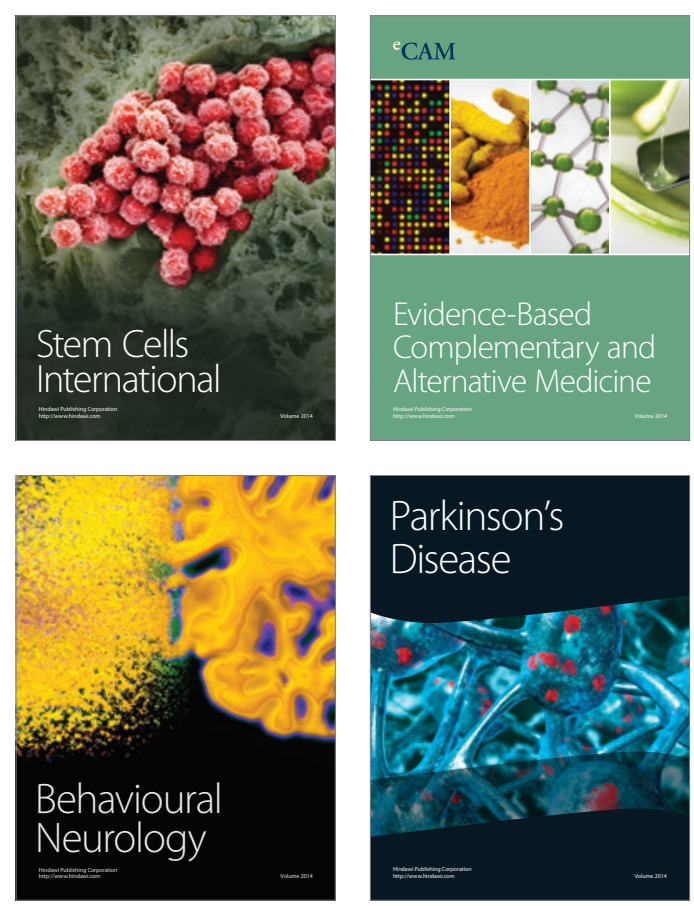

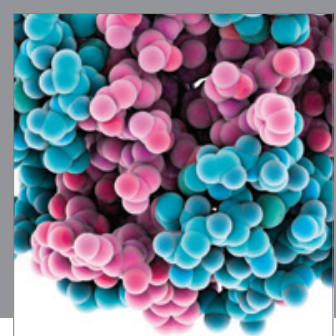

Journal of
Diabetes Research

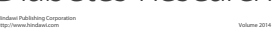

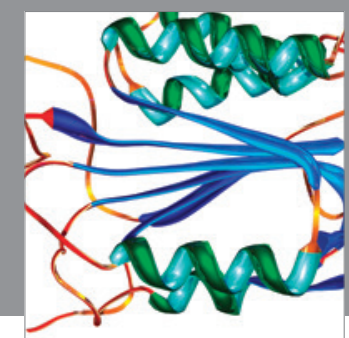

Disease Markers
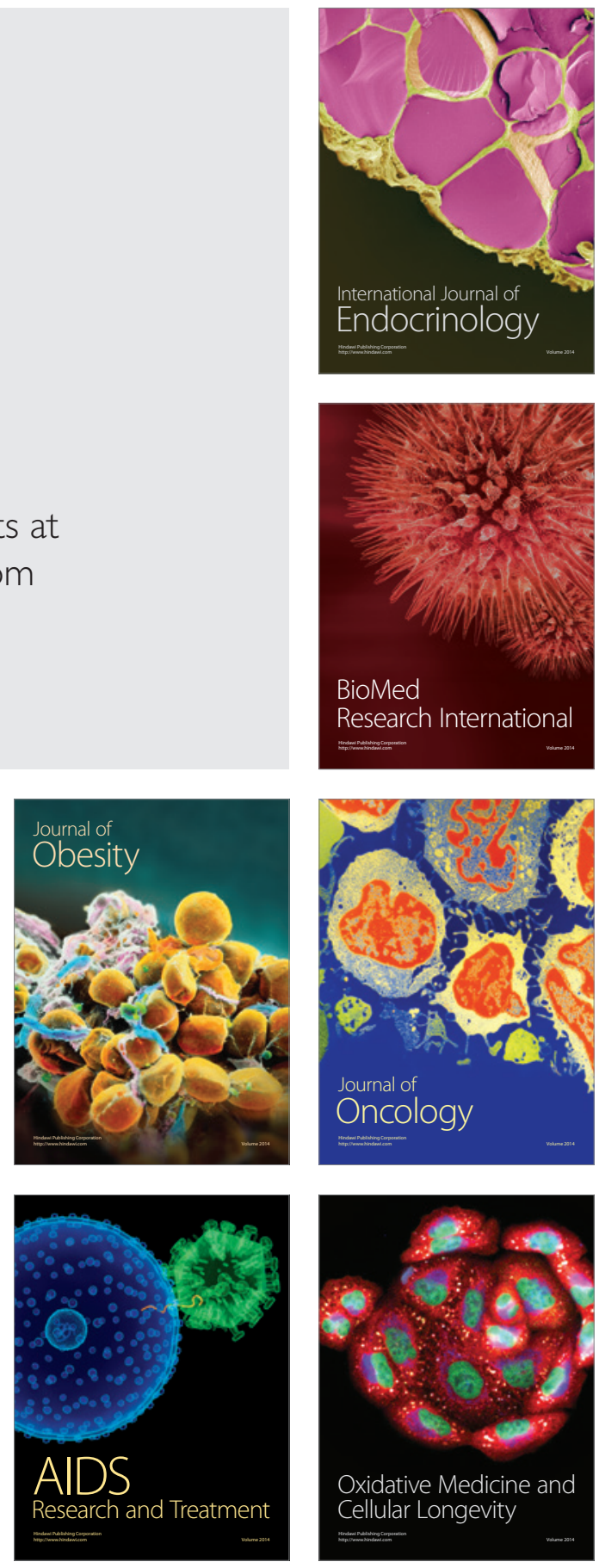